\title{
Mapping the Influence of Project Management Attributes on Project Cost
}

\author{
Jonathan Musonda ${ }^{1}$
}

${ }^{1}$ Zhejiang University of Science \& Technology

\begin{abstract}
This paper develops a framework to map the influence of project management (PM) attributes on project cost and then test these relationships between PM attributes and project cost on industrial construction projects. PM attributes are identified and classified into five areas: Human Resource Management (HRM), function of PM, partnering and supply chain, design efficiency, and quality. The framework is tested on survey data from construction companies and project management firms in China using the Structural Equation Modeling method. The results reveal that quality, function of PM, and HRM can have a significant positive impact on project cost. Quality is found to have the most direct and greatest impact on project cost efficiency among PM attributes. The goal of this statistical study is to demonstrate the paths and strengths of the effects of PM attributes on project cost.
\end{abstract}

Keywords: Project Management Attributes, Project Cost, Influence Framework, Structural Equation Modeling

\section{Chapter 1}

\subsection{Introduction}

Project management is the discipline of initiating, planning, executing, controlling, and closing of the work of a team to achieve specific goals and meet specific success criteria.

It would suffice to say, Project management and project cost are inseparable. The challenges of a project manager are, scope, cost, time and the project controller helps the project manager by fulfilling these roles. A project manager acts as the captain of a ship, while the project controller acts as the navigating officer of a ship. However, our focus will be on project cost, how it's influenced by the attributes of project management.

Project cost control is one of the most important management techniques that contribute to project success. Cost overrun is so frequent that it is occurs on nearly all construction projects (Azhar et al., 2008). History shows that significant cost overrun is endemic within the construction industry worldwide (Ameh, Soyingbe and Odusami, 2010) in both developing and developed countries (Angelo and Reina, 2002). It is widely acknowledged that the problem of cost overrun is critical and needs to be studied more to alleviate the issue. Various studies have been conducted to address the factors affecting project cost. Some of the problems include unavailability of materials, inflation, price fluctuation in material, project complexity, excessive amendments of design and drawings, poor coordination among participants, ineffective monitoring and feedback, lack of project leadership skills, cash flow and financial difficulties, contractor's poor site management and supervision, inadequate contractor experience, shortage of site workers, incorrect planning and scheduling, and other factors (UNRWA, 2006; Memon, 2010; Okpala and Aniekwu, 1988; Chan and Park, 2005). Among these causes, many are related to project management; consequently, a deeper understanding of the attributes that influence project cost control is crucial to improving project outcomes (Avots, 1969; Nguyen et al., 2004; Hasanzadeh et al., 2011). PM maturity has a positive relationship with project success (Ibbs and Kwak, 2000) and good project management in construction is correlated with lower cost (Ibbs and Reginato2002). Many PM factors cause variations on cost performance. Mansfield et al. (1994) concluded that most of the problems from delay and cost overruns on construction projects can be attributed to human resources and management problems, such as financial arrangements, poor contract management, materials shortage, inaccurate estimating, and overall price fluctuations. Poor site management in the form of resource and schedule planning, supervision and control, and lack of experience are also causes of cost and time overruns, as stated by Chan and Kumaraswamy (2002), Kaming et al. (1997), and Ogunlana etal. (2003). Chua et al. (1999) identified eight important project management attributes associated with achieving successful budget performance through an application of the neural network approach: (1) number of organizational levels between the project manager and craft workers, (2) amount of detailed design completed at the start of

This article is published under the terms of the Creative Commons Attribution License 4.0

Author(s) retain the copyright of this article. Publication rights with Alkhaer Publications.

Published at: http://www.ijsciences.com/pub/issue/2020-03/

DOI: 10.18483/ijSci.2296; Online ISSN: 2305-3925; Print ISSN: 2410-4477 
construction, (3) number of control meetings during the construction phase, (4) number of budget updates, (5) implementation of a constructability program, (6) team turnover, (7) amount of money expended on controlling the project, and (8) the project manager's technical experience. Project Management and project cost work hand in hand to have a successful project. More also, the need to alleviating cost overruns in order to have a successful project has never seized. However, there are different factors or attributes of Managing a project that each have a different impact or influence on project cost.

\subsection{Problem statement}

Cost in the success of a project is one critical aspect, as either a project is to be a success or fail or incur loses and cost overruns. Cost overruns have been a long existing problem, even though it cannot be totally avoided, many ways or methods have been sought to alleviate cost overruns. However, to effectively control costs, factors that affect the cost of a project differ, in this case we are referring to our scope -the attributes of project management. More also, these factors of PM, each has its own degree of influence on project cost, to control cost is not an easy task as it's not easy and direct to tell where cost overruns are emanating from because there are many factors at play, and each influencing cost unequally, thus it's only when an analysis is strictly done and knowing how and to what degree by placing a figure or value as to what each factor or attribute is influencing the cost of a project -project cost, only then would it be easier for a project manager as to which factors or attributes he should pay required attention in correspondence to their degree of influence on project cost, otherwise he would be overwhelmed by the overruns of costs without knowing the source. Approaches in using SEM in various projects e.g. Engineering have been used and in this case, MAPPING THE INFLUENCE OF PROJECT MANAGEMENT ATTRIBUTES ON PROJECT COST USING STRUCTURAL EQUATION MODELING.

\subsection{Research aim}

The aim of this research is to develop a framework for the influence of project management attributes on project cost using structural equation modeling ( SEM ) . This framework is able to help project managers and contractors and be a guide to attributes they should pay attention to correctly and correspondingly to each attribute's degree of influence on project cost as they carry out the proceedings of the project.

\subsection{Research objectives}

The main objectives of this study are:

1. Introduce structural equation modeling (SEM)

2. Use structural equation modeling, and

3. Map the influence of project management attributes on project using structural equation modeling (SEM) With the help of SEM software-AMOS

\subsection{Research importance}

Contributions of this paper are expected to be important to both researchers and practitioner's/project managers:

To researchers, the findings should help to investigate the degree of influence of each of the attributes on project cost.

For practitioners'/ project managers and contractors, the findings should help to alleviate cost overruns, manage project cost effectively in perspective when it comes to PM attributes by enabling them to appropriate inputs and attention correctly by responding with correct measures as this framework shows them what areas to pay attention to.

\subsection{Research Scope and Limitation}

This paper focuses on projects that were carried by various construction companies, project management firms and project manger's experiences in China. Then the framework was tested using the Structural Equation Modeling.

\subsection{Methodology Outline}

In order to achieve the above mentioned objective of the study -The influences of project management factors on project cost, will be evaluated by a set of influence coefficients. To establish these coefficients, the following research process is carried out:

(1) Identify key PMfactors through literature review

(2) Summarize and define PM attributes through liter ature review

(3) Establish a framework to map the influences of PM attributes on project cost to determine which of the variables influence outcomes (4) Collectproject data, perform reliability test, and d ata processing

(5)Select methods to test the influence framework m odel and calculate the influence coefficients

(6) Perform analysis and discuss results.

The research process and methods are shown in Fig 3.1 Questionnaire Design. After a thorough review of the literature, PM factors affecting cost were identified, summarized, and classified into eight areas and cost efficiency was selected as a project cost metric. Data for PM factors and cost efficiency were collected from 
construction companies and project management firms in China.

\subsection{Research Layout}

The current study included seven chapters explained as follows:

Chapter (1) An introductory chapter defines the problem statement, the objectives of this study, the methodology and an overview of this study. Chapter (2) Literature review presents a literature review of efforts that are related the attributes of project management, the Influence Framework of PM Attributes on Project Cost and the application of structural equation modeling (SEM) Chapter (3) Research methodology, the adopted methodology in this research was presented in this chapter including the data-acquisition process of influential PM attributes that relate to project cost and data necessary for modeling.

Chapter (4) Data results present statistical analysis for questionnaire surveying, factor analysis. It also presents the adopted influential factors in this study and the encoded data for model implementation.

Chapter (5) Model development presents the selected application software and type of model chosen and displays the model implementation as well as the results of the model, and influence factors of SEM are showed.

Chapter (6) presents conclusions and lastly,

Chapter (7) shows references

\section{Chapter 2}

\subsection{Introduction}

Project Management (PM) attributes are identified and classified into five areas: Human Resource Management (HRM), function of PM, partnering and supply chain, design efficiency, and quality.

The framework model is tested on survey data from construction companies and project management firms in China using Structural Equation Modeling method.

\subsection{Literature Review of PM Attributes Affecting Project Cost}

According to A Guide to the Project Management Body of Knowledge (PMI, 2004), project management is the application of knowledge, skills, tools, and techniques to a broad range of activities in order to meet the requirements of a particular project. Project management consists of nine knowledge areas: integration, scope, cost, time, quality, risk, human resources, communication, and procurement management. Having a cost target is one of the key project requirements. A comprehensive literature review was conducted to identify the major project management factors affecting project cost. Table 1 shows the major causes related to PM identified by the literature review. Based on the literature review results, the relevant causes for cost overrun that were related to PM were classified under a number of PM attributes. The PM attributes were selected based on their definition and associated activities and their availability as input measures in the CII 10-10 project performance assessment program.

Table 1. Summary of Studies in the Field of PM Attributes Affecting Project Cost

\begin{tabular}{|c|c|c|c|}
\hline No & Causes related to PM & References & PM attributes \\
\hline 1 & $\begin{array}{l}\text { Planning and scheduling by contractors: change in the scope of } \\
\text { the project. }\end{array}$ & $\begin{array}{l}\text { Azhar et al. (2008); Ameh et } \\
\text { al. (2010); Enshassi et al. } \\
\text { (2009) }\end{array}$ & Planning \\
\hline 2 & $\begin{array}{l}\text { Frequent design changes; Amount of detailed design at the start } \\
\text { of construction; Design effectiveness, }\end{array}$ & $\begin{array}{c}\text { Enshassi et al. (2009); Ameh } \\
\text { et al. (2010); Chua et al. } \\
\text { (1999); } \\
\text { Meeampol and Ogunlana } \\
\text { (2006) }\end{array}$ & Design efficiency \\
\hline 3 & Slow decision making; lack of project leadership skills & $\begin{array}{c}\text { Enshassi et al. (2009); } \\
\text { Sambasivan and Soon (2007); } \\
\text { Iyer and } \\
\text { Jha (2005); UNRWA (2006); } \\
\text { Memon et al. (2010) }\end{array}$ & Leading \\
\hline 4 & $\begin{array}{l}\text { Contractor's poor site management and supervision; Number of } \\
\text { control meetings during the construction phase; number of budget } \\
\text { updates }\end{array}$ & $\begin{array}{l}\text { Hoai and Lee (2008); Chua et } \\
\text { al. (1999); Azhar et al. (2008) }\end{array}$ & Controlling \\
\hline & Project managers technical experience; competence of project & Chua et al. (1999); & \\
\hline
\end{tabular}




\begin{tabular}{|c|c|c|c|}
\hline 5 & $\begin{array}{l}\text { team, Labor productivity; Team turnover; Shortage of site } \\
\text { workers; Lapses in the management of human resources }\end{array}$ & $\begin{array}{l}\text { Abdullah et al. (2009); } \\
\text { Memon et al. (2010); } \\
\text { Okpala and Aniekwu (1988); } \\
\text { Meeampol and Ogunlana } \\
\text { (2006) }\end{array}$ & $\begin{array}{l}\text { Human resource } \\
\text { management }\end{array}$ \\
\hline 6 & $\begin{array}{c}\text { Conflict or coordination among project participants; communication } \\
\text { among partners }\end{array}$ & $\begin{array}{c}\text { Iyer and Jha (2005); Meeampol } \\
\text { and Ogunlana (2006) }\end{array}$ & $\begin{array}{c}\text { Partnering and } \\
\text { supply chain } \\
\text { management }\end{array}$ \\
\hline 7 & $\begin{array}{c}\text { Number of organization levels between the project manager and } \\
\text { the craft workers; Poor contract management }\end{array}$ & $\begin{array}{l}\text { Chua and Loh (1999); } \\
\text { Mansfield et al. (1994) }\end{array}$ & Organization \\
\hline 8 & Mistakes during construction; Amount of work & $\begin{array}{l}\text { Palaneeswaran et al. } \\
\text { (2008); Hoai and Lee (2008); } \\
\text { Sambasivan } \\
\text { and Soon (2007); Josephson et } \\
\text { al. (2002) }\end{array}$ & Quality \\
\hline 9 & Contractor experience; Contractors financial management ability & Enshassi et al. (2008) & $\begin{array}{l}\text { Contractor's } \\
\text { experience }\end{array}$ \\
\hline 10 & Change orders due to enhancements requires by client & Nega (2008) & Owner \\
\hline
\end{tabular}

Table 2. Definitions of PM Attributes and Project Cost Efficiency

\begin{tabular}{|c|c|}
\hline PM factors/output metric & Explanation \\
\hline $\begin{array}{c}\text { Human resource } \\
\text { management }\end{array}$ & $\begin{array}{c}\text { Examines if the project is staffed correctly, with a minimum amount of staff turnover } \\
\text { and appropriate training. } \\
\text { Measures if people are capable of achieving project goals. }\end{array}$ \\
\hline Planning & $\begin{array}{l}\text { The work a manager performs to predetermine a course of action. The function of } \\
\text { planning includes the following activities: } \\
\text { forecasting, objective setting, program development, scheduling, budgeting, and policies } \\
\text { and procedures development }\end{array}$ \\
\hline Organizing & $\begin{array}{c}\text { The work a manager performs to arrange and relate the work to be done so people } \\
\text { can perform it most effectively. } \\
\text { The function of organizing includes the following activities: development of } \\
\text { organization structure, delegation of } \\
\text { responsibility and authority, and establishment of relationships. }\end{array}$ \\
\hline Leading & $\begin{array}{l}\text { The work a manager performs to cause people to take effective action. The activities } \\
\text { involved in the function of } \\
\text { leading include: decision-making, communications, motivation, selection of people, and } \\
\text { development of people }\end{array}$ \\
\hline Controlling & $\begin{array}{c}\text { The work a manager performs to assess and regulate work in progress and completed. } \\
\text { Management controls are } \\
\text { achieved through the following activities: establishment of performance standards, } \\
\text { measurement of performance, } \\
\text { evaluation of performance, and correction of performance. }\end{array}$ \\
\hline Design efficiency & $\begin{array}{l}\text { Measures if the project team is exhausting all techniques to optimize the design in its } \\
\text { use of material quantities to } \\
\text { provide maximum capacity at minimum cost. }\end{array}$ \\
\hline Partnering and supply chain management & $\begin{array}{c}\text { Examines the strategies used by the project team to promote enhanced working } \\
\text { relationships among all project } \\
\text { stakeholders including those in the project supply chain. }\end{array}$ \\
\hline Quality & $\begin{array}{c}\text { Measures if the project team is strictly conforming to project requirements. Analyzes if } \\
\text { programs are pursued to } \\
\text { assure the delivery of material goods as intended. }\end{array}$ \\
\hline Project cost efficiency & Forecasted total project cost / capacity \\
\hline
\end{tabular}

Note: Definitions of PM attributes and project cost efficiency are cited from CII document: The 10-10 Program (Kang et al., 2014) 
In the following sections, each attribute is discussed in more detail. Table 1 organizes the various PM-related causes for cost overrun found in the literature into ten categories including planning, design efficiency, leading, controlling, human resource management, partnering and supply chain management, organizing, quality, contractor's competence and owner. Contractor's competence and owner issues were excluded from this study because they are out of the project manager's control, although they do have an effect on cost. For simplicity, this study will refer to human resource management as HRM, partnering and supply chain management will be called supply chain, and project cost efficiency will simply be called cost efficiency. PM attributes and definitions will be presented in the next section.

\subsection{The Definitions of PM Attributes}

Ultimately, eight PM attributes were selected for inclusion in this study: human resource management, planning, organizing, leading, controlling, design efficiency, partnering and supply chain management, and quality. The objective and subjective questions contained in each questionnaire combine to create 10 input measures. The questionnaire can be seen at the back in the last chapter. The definitions of eight PM attributes are shown in Table 2. Total project cost is greatly affected by project size and project cost efficiency. Project cost efficiency is defined as the forecasted total project cost divided by capacity.

Better cost efficiency indicates less money spent on unit production capacity (such as megawatts for an electrical project). Since units of cost efficiency are different for different types of projects, in order to reduce data diversity, project cost efficiency was processed by logarithms.

\subsection{The Influence Framework of PM Attributes on Project Cost}

The purpose of this research is to map the relationships between PM attributes and project cost. In order to perform such an analysis, a suitable framework model between PM attributes and project cost is needed.

\subsection{Framework Structure}

In this framework, PM attributes, including planning, organizing, leading, controlling, HRM, supply chain, design efficiency, and quality are utilized along with project cost efficiency. The relationships between the PM attributes and cost efficiency were analyzed and the results are presented in chapter 5 .

Through examination on the definition of PM, it can be appreciated that: (1) the purpose of PM is to achieve project objectives; and, (2) PM functions include leadership, organization, planning, monitoring, and coordinating. On the other hand, the definition of management has been interpreted in many ways. For example, management can be defined as the art of getting things done through people (Norman, 2013). According to Leonard (2012), management is defined as what managers do. People are key to the success or failure of any management activity.

George (1982), identified four fundamental functions of management e.g., planning, organizing, actuating and controlling. According to Henry Fayol, to manage is to forecast and plan, to organize, to command, and to control. The major functions of management can be categorized into four different functions known as planning, organizing, leading, and controlling. For theoretical purposes, it may be convenient to separate the function of management but practically these functions are overlapping in nature. For example, they are highly inseparable. Each function blends into the other and affects the performance of others. The basic management functions which include planning, organizing, controlling and leading, are also required for the management of any project (Frigenti and Comninos, 2006; Stretton, 2015). Analytically, it may be convenient to distinguish the management functions separately but practically the functions overlap in nature and are inseparable. Each function blends into the other and affects the performance of others. The influence of PM attributes on project cost can be mapped in a preliminary framework, as shown in Fig. 1.

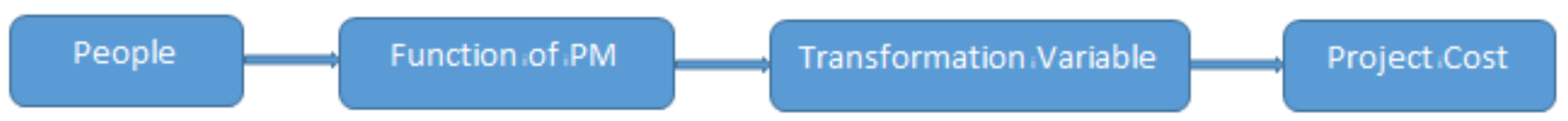

Fig. 1. Influence Framework Structure of PM on Project Cost 


\subsection{An Influence Framework}

It can be seen from Fig. 1 that people are the driving force of PM, and through the functions of management, the objectives of transformation variables and project cost are achieved. Human Resources (HR) is primarily concerned with the management of people within organizations. The Function of PM is a combination of planning, organizing, leading, and controlling and it leads to transformation variables such as supply chain, design efficiency and quality. In the study project cost refers to cost efficiency. The relationships between HR, supply chain, design efficiency, quality, and cost efficiency will be discussed. Human Resource Management (HRM) is a fundamental function of PM (Belout and Gauvreau, 2004). Many researchers agree that HRM is one of the most crucial elements that contribute to an organization's success (Fabi and Petersen, 1992; Ulrich, 1987; Schultz et al., 1987). The basis for quality is that in general, things should be "done right" the first time and "rework" should be avoided. Quality is regarded as one of the prime indicators of a successful construction project and Quality Management $(\mathrm{QM})$ is an integral part of the project management process. It enables and contributes to a process-oriented and transparent project management approach across all project phases (ISO10006). The quality of the entire project is a function of the collective sum of many inputs including quality of design, construction, operations and maintenance, management participation, good design with sufficient experience, cooperation and coordination between parties in the design and construction phases, consistent design drawings and specifications, good communications with owner, and selection of appropriate designers and contractors (Wilson, 1999). One study showed that effective management of quality can be ensured from the conceptual design stage of the project (Oyedele et al., 2003). QM in projects covers those activities to meet the project requirements in terms of functionality, costs, and deadline, therefore QM can lead to cost variation (ISO10006). The objective of QM in projects is to fulfill contractual obligations and obtain the appropriate level of customer satisfaction. Quality has traditionally been interpreted as the ability to satisfy needs, conformance to requirements, and fitness for purpose (Husin, 2008; ISO10006). Poor attention has been given however, to quality in relation to the cost of construction. Actual quality is cost-sensitive (Idiake, 2015). Supply chain management describes the discipline of optimizing the delivery of goods, services and related information from supplier to customer (Cooper et al., 1997). Efficiently and effectively managing the flow of material from supply sources to theultimate customer involves proper design, planning and control of supply chains, and offers opportunities in terms of quality improvement, cost and lead time reduction (Persson, 2002), and rapid response to changes or new developments (Bowersox, 1996). Different supply chains link with the distinct result in quality and costs. (Persson, 2002). Low costs can always be attributed to good decisionmaking during product design (Ehrlenspiel, 2007) Improving construction design through the application of the lean thinking paradigm could improve the designer's cost and program visibility when choosing between design options to increase the cost efficiency. (Morris, 1999). The quality of design is associated with cost efficiency. Based on the above analysis between PM attributes and project cost, two experts from CII were interviewed to provide a deeper insight into relationships between PM attributes and project cost. The relationships between the factors and the rationality of the framework were discussed. The two experts both agreed that direct impacts of supply chain management and design efficiency on cost efficiency were not significant and that the two causal relationships could be cut out. A causal relationship framework was developed and shown in Fig. 2. The blue lines indicate causal relationships between factors and the two red lines indicate that the direct impacts of supply chain management and design efficiency on cost efficiency do not need to be considered according to the two experts' suggestion. The framework without the two red lines is named model $\mathrm{A}$ and the framework with the two red lines is named model B. The comparison of the two models will be discussed in chapter 5.2.1 
Model B

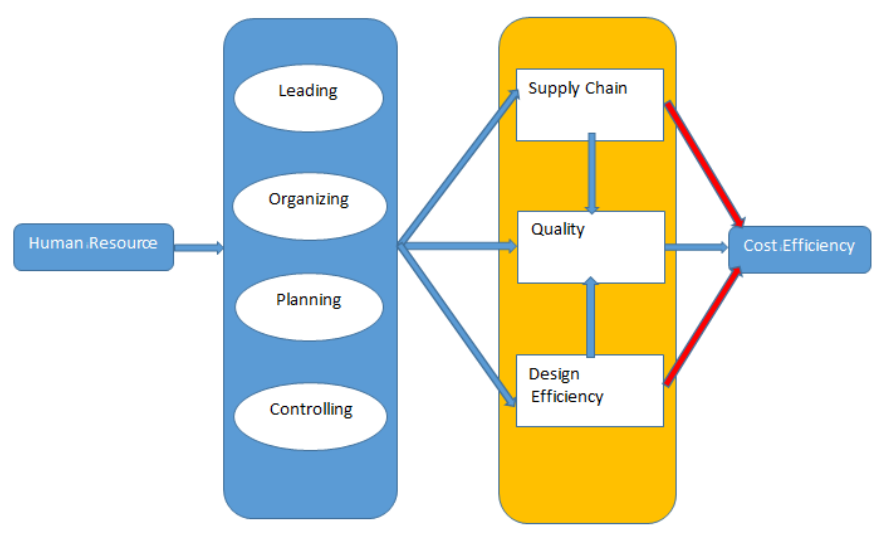

Fig. 2. The influence Framework Indicating Relationships between PM attributes and Project Cost

\subsection{Hypothesis}

Based on the influence framework model A, seven proposed relationships between factors hypothesized as follows:

H1. HRM is positively correlated with improved function of the PM effort.

H2. The PM function is positively correlated with improved supply chain.

H3. The PM function is positively correlated with improved Quality.

H4. The PM function is positively correlated with improved design efficiency.

H5. Quality is negatively correlated with cost efficiency.

\subsubsection{Structural Equation Modeling}

Structural equation modeling is a multivariate statistical analysis technique that is used to analyze structural relationships. This technique is the combination of factor analysis and multiple regression analysis, and it is used to analyze the structural relationship between measured variables and latent constructs. This method is preferred by the researcher because it estimates the multiple and interrelated dependence in a single analysis. In this analysis, two types of variables are used endogenous variables and exogenous variables. Endogenous variables are equivalent to dependent variables and are equal to the independent variable.

\subsection{Factor Analysis}

Factor analysis is a technique that is used to reduce a large number of variables into fewer numbers of factors. This technique extracts maximum common variance from all variables and puts them into a common score. As an index of all variables, we can use this score for further analysis. Factor analysis is part of general linear model (GLM) and this method also assumes several assumptions: there is linear relationship, there is no multi-collinearity, it includes relevant variables into analysis, and there is true correlation between variables and factors. Several methods are available, but principle component analysis is used most commonly.

\subsubsection{Factor Loading}

Factor loading is basically the correlation coefficient for the variable and factor. Factor loading shows the variance explained by the variable on that particular factor. In the SEM approach, as a rule of thumb, 0.7 or higher factor loading represents that the factor extracts sufficient variance from that variable.

\subsubsection{Key concepts and terms}

Exploratory factor analysis: Assumes that any indicator or variable may be associated with any factor. This is the most common factor analysis used by researchers and it is not based on any prior theory.

Confirmatory factor analysis (CFA): Used to determine the factor and factor loading of measured variables, and to confirm what is expected on the basic or pre-established theory. CFA assumes that each factor is associated with a specified subset of measured variables. It commonly uses two approaches:

The traditional method: Traditional factor method is based on principle factor analysis method rather than common factor analysis. Traditional method allows the researcher to know more about insight factor loading.

The SEM approach: CFA is an alternative approach of factor analysis which can be done in SEM. In SEM, we will remove all straight arrows from the latent variable, and add only that arrow which has to observe the variable representing the covariance between every pair of latent. We will also leave the straight arrows error free and disturbance terms to their respective variables. If standardized error term in SEM is less than the absolute value two, then it is assumed good for that factor, and if it is more than two, it means that there is still some unexplained variance which can be explained by factor. Chi-square and a number of other goodness-of-fit indexes are used to test how well the model fits. 


\subsection{AMOS}

AMOS is statistical software and it stands for analysis of a moment structures. AMOS is an added SPSS module, and is specially used for Structural Equation Modeling, path analysis, and confirmatory factor analysis. It is also known as analysis of covariance or causal modeling software. AMOS is a visual program for structural equation modeling (SEM). In AMOS, we can draw models graphically using simple drawing tools. AMOS quickly performs the computations for SEM and displays the results.

\section{Chapter 3}

\subsection{Introduction}

This chapter discusses the methodology used in this research. The adopted methodology to accomplish this study used data analysis as the base of PM attributes affecting or influencing project cost. This chapter provides the information about the research strategy, the influence of PM attributes on project cost.

\section{2 research strategy}

Research strategy in general means a plan of action which the research objectives can be questioned, and this may be classified into two -Quantitative approach and Qualitative approach.

The Qualitative approach seeks to gain insights and to understand people's perceptions, or opinion towards a particular subject. As well, it's used when limited amount of knowledge about the topic is available.

Quantitative approach seeks to collect factual data and to study relationship between facts and how such facts and relationships accord with theories and findings of any research executed previously. In this study both qualitative and quantitative approaches were used to get the factual information of the influence of PM attributes on project cost. As well as data collection from several resources by filling a form.

\subsection{Research design}

Figure 3.1 Research Flowchart

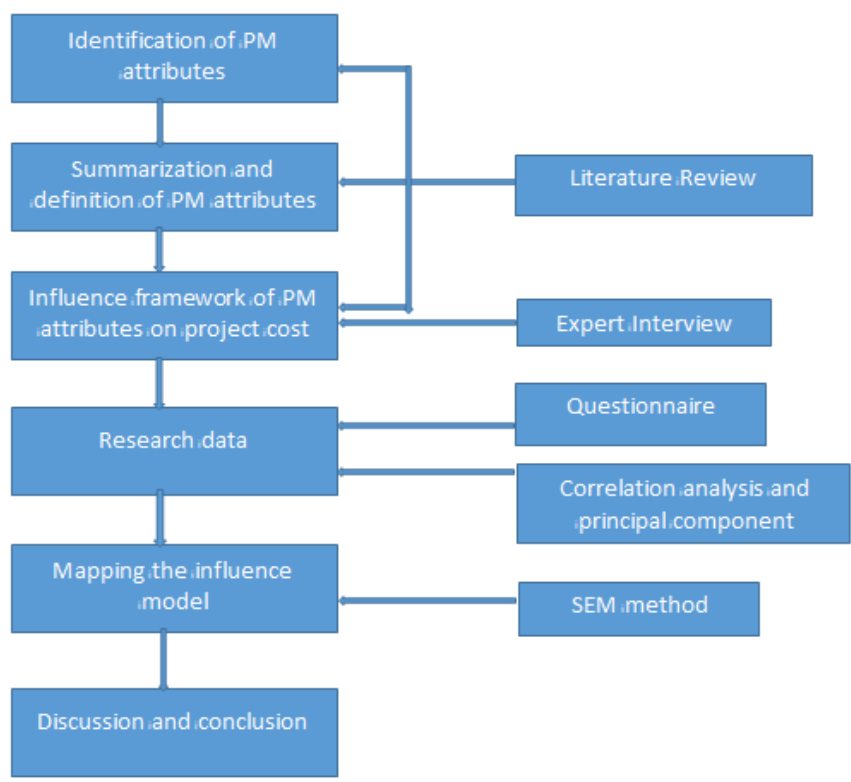

\subsection{Pearson's Correlation Analysis and Principal Component Analysis}

The relationships between PM factors and project cost were studied based on the review of the theoretical and empirical literature. Project management functions can be classified into four types of activities, planning, organizing, leading, and controlling. Using the collected industrial construction projects data, the relationships between the four types of activities were tested quantitatively using the Pearson correlation analysis method. Statistical analysis of the data showed that these PM functions are significantly correlated with each other. Therefore, a new, independent variable was created to replace the four activity types using principal component analysis.

\subsection{Expert Interview}

Fig. 3.1. Research Flowchart Based on the relationships of PM attributes and project cost, a Mapping the Influence of Project Management on Project Cost relational framework was developed. In addition to the questionnaire survey, experts from engineering construction companies and project management firms were interviewed -project manager at top management level.

\subsection{Structural Equation Modeling Method}

It is important to assess the internal validity of the relational framework model from a statistical perspective. Structural Equation Modeling (SEM) is a statistical method designed to test a 
conceptual or theoretical model (Kline, 2010). SEM is defined as a statistical methodology that takes a confirmatory approach to the analysis of a structural theory bearing on some phenomenon and includes two components. First, the causal relationships under study must be represented by a series of structural equations and second, these structural relationships are then modeled pictorially to enable a clearer conceptualization of the theory under study. SEM provides a method for statistically testing hypothesized relationships between variables simultaneously to determine the extent to which the model is consistent with the data (Bryne, 2001; Schumacher et al., 2004). SEM has been used in some studies to determine the influence of project management on project performance (Gowan and Mathieu, 2005; Sambo Zulu 2007), for example. In this study, confirmation was needed to determine whether the data from the industrial construction projects fit the relational framework model. This can be examined using SEM, and so the validity of the framework model to determine how project management factors affect project cost and the proposed hypothesis were tested. Another strength of the SEM method is that it accounts for both the direct relationships between variables and indirect relationships between PM attributes and project cost. Thus, the use of SEM improves the understanding of both direct and indirect influences of PM attributes on project cost.

\section{CHAPTER 4}

\subsection{Questionnaire Analysis}

Over 200 questionnaires were distributed to various Engineering construction companies and project management firms 130 questionnaires were successfully filled in. The total number had been correctly answered and submitted. These questionnaires were evaluated and some of which were omitted due to inaccurate data. More details and analysis are discussed in this section for questionnaire results.

After a thorough review of the literature, PM factors affecting cost were identified, summarized, and classified into eight areas and cost efficiency was selected as a project cost metric. Data for PM factors and cost efficiency were collected from engineering construction companies and project management firms in China who responded to the survey.

In this study, only data from industrial construction projects was considered. The next section deals with PM factors and asks the respondents to select by ticking the degree of influence or impact of each of the factors of project management on the cost of a project by rating on the scale of 1 to 7 tick on each of these factors to denote the degree to which each one influences project cost on a project, from a range of responses e.g., very low, moderate, and very high, about statements related to PM practices. Responses are scored using a scale from 1 to 7 , where 1 means "very low influence" compared to what was expected or planned and 7 means an "every high influence" and a middle figure i.e. 4, to mean moderate influence compared to what was expected or planned.

\subsection{Research Data}

This section provides a description of the project data that were collected from construction companies and project management firms and a discussion of the statistical and reliability tests that were performed. Among the eight-selected PM factors, planning, leading, controlling, and organizing are related PM functions, and the correlation degree between the PM functions was expected to be high, from a theoretical perspective. Correlation analysis was used to get the correlation coefficients between planning, leading, controlling, and organizing, and if the correlation coefficients between PM attributes were found to be high then principal component analysis can be used to reduce the PM functions and make independent variables. The remaining PM attributes are evaluated in later sections.

\subsection{Data Collection}

Through the project-level survey, the data were gathered from industrial construction projects executed mainly in China. The questionnaire collects responses on factors including HRM, leading, planning, controlling, organizing, design efficiency, supply chain, quality, and cost efficiency. Ultimately, data from projects were used in the analysis. The Statistical Package for Social Science (SPSS) version 17.0 was used to analyze the data. According to the geographical distribution of project location the projects were located in the CHINA. Construction projects are the focus of this research.

\subsection{Reliability Test}

Reliability testing depicts the degree of consistency of the data collected. The Cronbach $\alpha$ coefficient is a measure of inner consistency. Reliability is low when Cronbach $\alpha$ is less than 0.3 and it cannot be accepted. Reliability is high when Cronbach $\alpha$ is more than 0.7 where 
it indicates the inner consistency is at a high level and is therefore highly acceptable. The value of alpha is desirable with a range higher than 0.5 to 0.6 (Nunnally, 1978; Meeampol and Ogunlana, 2006). The eight PM factors are related to attitude and are subjective, whereas cost efficiency is an objective variable, so the Cronbach $\alpha$ coefficient was done to test inner consistency for the eight subjective variables. The values of Cronbach $\alpha$ for the PM attributes are shown in Table 3, and from Table 3 it can be seen that all of the values of alpha are more than 0.6, which indicates that the inner consistency for the eight PM attributes is highly acceptable. The Cronbach $\alpha$ result for the whole index in this study is 0.936 and therefore it can be concluded that the questionnaire has reliability and stability.

Table 3. The Values of Cronbach $\alpha$ for Eight PM Attributes

\begin{tabular}{c|l} 
& Cronbach \\
\hline HRM & 0.676 \\
Planning & 0.702 \\
Organizing & 0.731 \\
Leading & 0.689 \\
Controlling & 0.603 \\
Quality & 0.632 \\
Design & 0.664 \\
efficiency & \\
Supply & 0.831 \\
Chain & \\
\hline
\end{tabular}

4.5 Correlation Analysis

Correlation is a term that refers to the strength of a relationship between two variables.
Correlation analysis is used to test the significance of the relationship between two variables. The Pearson correlation coefficient is a measure of the strength and direction of the linear relationship between two variables that is defined as the (sample) covariance of the variables divided by the product of their (sample) standard deviations. It is widely used in the sciences as a measure of the degree of linear dependence between two variables. Pearson's correlation coefficient is the covariance of the two variables divided by the product of their standard deviations (Karl Pearson, 1895; Gayen, 1951). Planning, leading, controlling, and organizing are the main functions of PM, and from the theoretical perspective, the four factors are related with each other and highly inseparable. In order to make new independent variables, correlation analysis of the four PM functions was carried out. The result of correlation coefficients is shown in Table 4. The result shows that the correlation coefficient between organizing and leading is 0.768 , which is the highest, followed by the correlation coefficient between organizing and controlling at 0.765. The correlation coefficients between leading and controlling, leading and planning, planning and organizing were $0.744,0.727$, and 0.686, respectively. The smallest correlation coefficient was between planning and controlling, at 0.672 . The results confirm that planning, leading, controlling, and organizing are significantly correlated with each other since the correlation coefficients are in the range of 0.6 to 0.8 , are very high.

Table 4. Pearson Correlation Coefficients between Planning, Organizing, Leading and Controlling

\begin{tabular}{|c|c|c|c|c|}
\hline & Planning & Organizing & leading & controlling \\
\hline Planning & 1 & $.686 "$ & $.727 "$ & $.672 ”$ \\
\hline Organizing & $.686 "$ & 1 & $.768 ”$ & $.765 ”$ \\
\hline leading & $.727 "$ & $.768 ”$ & 1 & $.744 ”$ \\
\hline controlling & $.672 "$ & $.765 ”$ & $.744 ”$ & 1 \\
\hline
\end{tabular}

\subsection{Principal Component Analysis}

Since planning, organizing, leading and controlling were found to be significantly correlated with each other a new independent variable comes into being to replace the original four factors, using principal component analysis. Principal Component Analysis (PCA) is a statistical procedure that uses an orthogonal transformation to convert a set of observations of possibly correlated variables into a set of values of linearly uncorrelated variables called principal components. The number of principal components is less than or equal to the number of original variables (Jolliffe, 2002). The results of the principal component analysis using data from 57 industrial projects are shown in Table 5. According to the Kaiser-Meyer-Olkin (KMO) and Bartlett's test, the measure of sampling adequacy is 0.851 , which is greater than 0.7 , showing that the effect of factor analysis is good. Bartlett's test of sphericity is 155.194 and the $\mathrm{P}=0.000$, which is less than 0.05 (Contreras, 2011), showing that the original hypothesis is rejected and factor analysis can be 
done. According to total variance as explained in Table 5, one common factor is extracted

\section{7 data collection}

The process of collecting data, some could not give or provide raw data. However, the methodology of collecting data and questionnaires being filled was based on going in person to these construction companies and project management firms. Through the projectlevel survey, the data were gathered from industrial construction companies and project management firms in Hangzhou, China. projects executed from 2010-2016. The questionnaire collects responses on factors including HRM, leading, planning, controlling, organizing, design efficiency, supply chain, quality, and cost efficiency.

\section{8 data validation}

The Statistical Package for Social Science (SPSS) version 17.0 was used to analyze the data.

\section{Chapter 5}

\subsection{Introduction}

Mapping the Influence of PM Attributes on Project Cost Using SEM Method with the influence framework set up, assessment of the internal validity of the framework model from the statistical perspective is the next step. The SEM method was selected to statistically test the hypotheses based on the influence framework model, upon which the quantitative map of the influence of PM attributes on project cost is founded. SEM analysis includes two approaches: covariance based SEM (CBSEM) and partial least squares based SEM (PLS-SEM). CB-SEM involves a maximum likelihood procedure whose goal is to minimize the difference between the observed and estimated covariance matrices, as opposed to maximizing explained variance. CB-SEM is more applicable to confirmatory factor analysis and PLS-SEM is more suitable for exploratory work in finding and evaluating causal relationships (Byrne, 2002; Hair et al., 2013). Therefore, CB-SEM was chosen to map the influence of PM attributes on project cost because the relational framework model is developed and the validity of the model needs to be confirmed. The significance was estimated by CB-SEM on Amos 17.0 software using 57 samples. Recommendations for determining sample size, based on the number of parameters to be estimated (Deborah, 1997). The number of observations per parameter estimate was contrasted by the measured variable parameter estimates. The ratio of sample size to number of parameters (namely $\mathrm{N}$ : q) might be able to go as low as 5:1 under normal and elliptical theory (Bentler et al., 1987). Jackson suggested that in the context of confirmatory factor analysis, N: q values could be 10:1 or more (Jackson, 2003). The question of how large of a sample size is required is a deceptively difficult one to answer. Bentler considered that higher values of the observations per parameter ratio had a positive effect for some measures of fit. However, the overall effect was small relative to sample size (Bentler et al., 1987). In the study, there are six variables and no latent variables, and according to the influence framework (in Fig. 3) there are seven parameters to be estimated. Based on the ratio of 5:1 the sample number should be greater than or equal to 35 , or based on the ratio of $10: 1$, the sample number should be greater than or equal to 70 . Consequently, the 57 samples in the study are acceptable. The normality of the variables was tested because the significance probabilities are estimated by the maximum likelihood method (Tenenhaus et al., 2005). One sample Kolmogorov-Smirnov test was performed and the result is shown in Table 6. From the result, the asymptotic significance for cost efficiency was found to be 0.000 , which is less than 0.05 , indicating that the cost efficiency data is not normally distributed. The asymptotic significance of all other variables were higher than 0.05 , indicating that the other variables are normally distributed. Data for cost efficiency was transformed by the logarithm function and the transformed data is normally distributed. The data for HRM, function of PM, design efficiency, quality, supply chain, and the transformed data of cost efficiency were included in the SEM analysis.

\subsection{Model Building}

\subsubsection{Comparison of Two Framework Models}

With the framework model A and B, assessment and comparison of the internal validity of the two models will be carried out using the SEM method. The values of $\chi 2 / \mathrm{df}$ for model $\mathrm{A}$ and model B are respectively 1.232 and 1.514 (if 1 $<2 \chi /$ df $<2$, the model is acceptable), which shows that two model fits are both acceptable. AIC and ECVI for model A and model B are shown in Table 7. AIC, BCC, BIC, and CAIC of model A are smaller than those of model B. The ECVI and MECVI values of model $A$ are also smaller than those of model B. Therefore, model $\mathrm{A}$ is more suitable for the data than model B (Minglong $\mathrm{Wu}, 2010$ ), and the impacts 
of supply chain and design efficiency on cost efficiency are confirmed to not be significant. This result is consistent with two experts' suggestion that direct impacts of supply chain and design efficiency on project cost were not significant. Consequently, the two causal relationships can be cut out and model $\mathrm{A}$ is used for further study.

Table 6. One Sample Kolmogorov-Smirnov Test of Variables

\begin{tabular}{|c|c|c|c|c|c|c|}
\hline & $\begin{array}{l}\text { Human } \\
\text { Resources }\end{array}$ & $\begin{array}{l}\text { Function of } \\
\text { PM }\end{array}$ & $\begin{array}{l}\text { Design } \\
\text { efficiency }\end{array}$ & Quality & Supply chain & Cost efficiency \\
\hline Mean & .6253 & 1.3013 & .5054 & .6323 & .6409 & 369468.55 \\
\hline Std. deviation & .09450 & .20260 & .18079 & .12541 & .16597 & 848272.25 \\
\hline $\begin{array}{l}\text { Kolmogorov- } \\
\text { smirnov } Z\end{array}$ & .670 & .724 & 1.260 & .710 & .897 & 2.481 \\
\hline $\begin{array}{l}\text { Asymp. Sig (2- } \\
\text { tailed) }\end{array}$ & .761 & .671 & .084 & .695 & .397 & .000 \\
\hline
\end{tabular}

Table 7. AIC and ECVI for Model A and Model B

\begin{tabular}{|l|l|l|l|l|l|l|l|l|}
\hline Model & AIC & BCC & BIC & CAIC & ECVI & LO 90 & H1 90 & MECVI \\
\hline Model A & 35.855 & 39.647 & 62.185 & 75.185 & 0.652 & 0.618 & 0.879 \\
\hline Model A & 39.085 & 43.46 & 69.465 & 84.465 & 0.711 & 0.655 & 0.934 \\
\hline
\end{tabular}

Table 8. Goodness of Fit Indices for the Measurement Model A

\begin{tabular}{|c|c|c|}
\hline $\begin{array}{ll}\text { Chi-square } & \text { Fit index }\end{array}$ & ACCEPTABLE FIT & $\begin{array}{r}\text { INDICES FOR DATA } \\
9.855\end{array}$ \\
\hline$D f$ & & 16 \\
\hline$P$ & $>0.05$ & 0.275 \\
\hline$X^{2} / d f$ & $\leq 2$ to 5 & 1.232 \\
\hline$R M R$ & $<0.06$ & 0.022 \\
\hline$G F I$ & $\geq 0.90$ & 0.946 \\
\hline RMSEA & $\leq 0.05$ to 0.08 & 0.065 \\
\hline CFI & $\geq 0.90$ & 0.984 \\
\hline$N F I(T L I)$ & $\geq 0.90$ & $0.924(0.97)$ \\
\hline IFI & $\geq 0.90$ & 0.985 \\
\hline
\end{tabular}

\subsubsection{Goodness-of-fit Indices for the Framework}

\section{Model A}

The validity and reliability of the constructs in model A were estimated and a further examination in Table 8 of the goodness of-fit indices for model A shows that the model is a relatively good fitting model. It is generally recommended to use a range of indices in order to assess a model (Schumacher and Lomax, 2004). An examination of the fit indices in Table 8 shows that model A fits the data fairly well. If the $\chi 2$ has a p-value $>0.05$ then the model is acceptable (Hair et al., 1998). In this case the $\chi 2$ value of $9.855(\mathrm{p}=0.275)$ suggests that the model is acceptable. At the same time the values of RMR, GFI, CFI, NFI, RMSEA and IFI show that the model A fits well (Hair et al., 1998) and the influence framework is acceptable.

\subsubsection{Evaluation of Model A: Hypothesis Testing}

Model A was tested on the Amos software with all the relationships shown in Fig. 2. The path coefficients represented by the regression weights are presented in Table 9. Based on the estimates it can be concluded that some relationships are confirmed. For example, the regression weight for HRM in the prediction of Function of PM is significantly different from zero at the .001 level (two-tailed), which means that HRM has a significant impact on the Function of PM. Table 9 displays the findings of the structural equation model that tests the seven hypotheses. From the results of hypothesis tests, five of the seven hypotheses were confirmed. It was confirmed 
Figure 4 Significant Paths of the Influence Framework

Model A

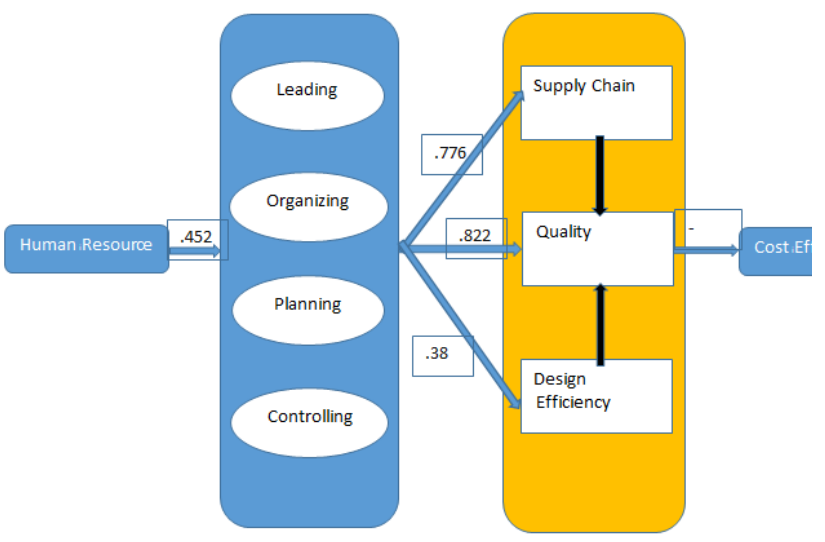

Figure note: blue arrows indicate statistically confirmed relationships and the numbers on the solid arrows indicate correlation coefficient values (standardized). Black color arrows indicate statistically unconfirmed relationships.

Fig. 3. Significant Paths of the Influence

Framework

that HRM has a statistically significant influence on the Function of PM since the C.R. value exceeds the 1.96 threshold. The Function of PM was found to have a statistically significant influence on quality, design efficiency and supply chain. Quality was shown to have a statistically significant influence on cost efficiency. The other two relationships were not confirmed, however. The impacts of supply chain and design efficiency on quality were not found to be statistically significant. The findings from the analysis summarized in Table 9 were mapped and are shown in Fig. 3 in the following section.

\subsubsection{Model Results}

\subsubsection{Results and Findings}

The statistically negative relationship found between PM attributes and project cost was consistent with previous research, (Chua et al., 1999; Azhar, Farooqui and Ahmed, 2008). SEM results show that the rational framework is accepted when $\chi 2$ value of 9.855 ( $\mathrm{p}=0.275>$ 0.05). This indicates that the chance of reduction of project cost can be significantly increased by improving the level of performance of PM attributes. In the influence framework model A, among 7 causal relationships (or hypotheses) 5 causal relationships (or hypotheses) were statistically confirmed. Fig. 3 shows the influence framework with statistically confirmed relationships and their standardized correlation coefficient values. The correlation coefficient values indicate the strength and direction of the impact between variables, and the larger the correlation coefficient value, the greater impact of the first variable upon the other one. Cost efficiency, HRM, and quality are discussed in the following paragraphs.

Table 9. Results of Hypothesis Tests

\begin{tabular}{|l|c|c|c|c|c|}
\hline & $\begin{array}{c}\text { Estimate } \\
\text { (standardized) }\end{array}$ & S.E. & C.R. & p & Conclusion \\
\hline Function of PM<---HRM & 0.452 & $\mathbf{0 . 2 5 8}$ & $\mathbf{3 . 7 6}$ & $* * *$ & Confirmed \\
\hline Design Efficiency<---Function of PM & 0.38 & $\mathbf{0 . 1 1 1}$ & $\mathbf{3 . 0 4 3}$ & $* *$ & Confirmed \\
\hline Supply Chain<---Function of PM & 0.776 & $\mathbf{0 . 0 7}$ & $\mathbf{9 . 1 2 5}$ & $* * *$ & Confirmed \\
\hline Quality<---Function of PM & 0.822 & $\mathbf{0 . 0 9 1}$ & $\mathbf{5 . 5 7 9}$ & $* * *$ & Confirmed \\
\hline Quality<---Supply Chain & $\mathbf{- 0 . 1 3 2}$ & $\mathbf{0 . 1 0 8}$ & $\mathbf{- 0 . 9 2 3}$ & $\mathbf{0 . 3 5 6}$ & Not confirmed \\
\hline Quality<---Design Efficiency & $\mathbf{0 . 0 5}$ & $\mathbf{0 . 0 6 7}$ & $\mathbf{0 . 5 1 6}$ & $\mathbf{0 . 6 0 6}$ & Not confirmed \\
\hline Cost Efficiency<---Quality & $\mathbf{- 0 . 2 7 2}$ & $\mathbf{4 . 7 2 9}$ & $\mathbf{- 2 . 0 9 5}$ & $*$ & Confirmed \\
\hline
\end{tabular}

***Correlation is significant at the 0.001 level; **correlation is significant at the 0.01 level; *correlation is significant at the 0.05 level.

\subsubsection{Impact paths of project cost}

Three paths were found where HRM affects cost efficiency: the first path is HRM-Function of PM-quality-cost efficiency, the second is
HRM-Function of PM-supply chain quality-cost efficiency, and the third path is HRM-Function of PM-design efficiency-quality-cost efficiency. The HRM Function of PM-quality-cost 
efficiency path was statistically confirmed and the standardized path coefficient of HRM affecting cost efficiency is -0.101 , which indicates that the improvement of HRM can indirectly explain $10.1 \%$ of a project's variation in cost efficiency. The paths where Function of PM affects cost efficiency are the same as HRM affecting cost efficiency. The Function of PM-quality-cost efficiency path was statistically confirmed and the standardized path coefficient of Function of PM affecting cost efficiency was -0.224, which indicates that PM function improvement can indirectly lead to better cost efficiency with Function of PM explaining 22.4\% of the variation in cost efficiency. Quality was confirmed to directly affect cost efficiency. The path coefficient is -0.272 which indicates that improvement of quality can explain $27.2 \%$ of the variation in cost efficiency. Based on the statistically confirmed paths of the influence framework there were three PM attributes that directly and indirectly affected project cost, with quality as the most significant factor, Function of PM is the second most significant factor and HRM is the third.(2) The impact of the Function of PM on transformation variables The impact of Function of PM on quality was found to be the largest, followed by the impact of Function of PM onsupply chain, and then the impact of Function of PM on design efficiency. Through the improvement of Function of PM, the level of supply chain and quality could be increased significantly. In contrast, improvement of Function of PM was found to increase the level of design efficiency, but not significantl.(3) The Quality Factor• Quality is at the core of the influence framework. Quality is related to PM functions as well as project cost. The impact of quality on cost efficiency was negative and not found tobe significant however

\section{Chapter 6}

\subsection{Conclusions}

It is widely acknowledged that the effectiveness of the Project Management (PM) effort is linked with project performance overall.

According to the results of the SEM and hypothesis tests, it was confirmed that there are significant relationships between PM attributes and project cost. Five hypotheses among the original seven were proved significantly. The HRM-Function of PM-quality-cost efficiency path was confirmed significantly, showing that HRM, the function of PM and quality can improve cost efficiency. The impact of quality on cost efficiency was the greatest, with quality explaining $27.2 \%$ of the variation in cost efficiency. Quality is proved to have the most direct and greatest impact on project cost efficiency among PM attributes. However, the increased cost caused by improving Quality, PM functions, or HRM will offset cost reduction, and so the level of quality, PM functions, and HRM cannot break through the critical points. From the results, this research provides paths and strengths of the impact of PM attributes on project cost and enriches the project cost management body of knowledge. Specifically, the primary contribution of this research will be to help project managers and contractors reduce project cost by improving the levels of HRM, Function of PM, and quality in construction process. If the project is staffed correctly and if people are capable of achieving project goals, a project manager can improve planning, organizing, leading, and controlling. This supports the efforts of the project team to strictly conform to project requirements and to pursue programs to assure the delivery of material goods as intended. Such efforts will lead to reduction in project cost. The authors therefore recommend that project managers on cost-driven projects should give explicit attention to improving HRM, PM functions, and quality. Secondly, the results can help decision-makers to select whether to focus on HRM, Function of PM, or quality, according to the focus on cost objectives of each unique project. A decision maker could select quality as the most efficient aspect to improve to revise current deviation from target in project cost. Finally, in the academic field, the results could provide a premise for further study on how deeply HRM, Function of PM, and quality influence project cost in order to find the specific measures to solve the project cost overrun. In summary, the influence framework was confirmed statistically but further research is encouraged to determine the relationships between supply chain, design efficiency, and quality. Additional data from a broader range of project types could also enrich the model and expand its applicability to other sectors. Because the level of quality, PM functions, and HRM cannot break through the critical points, the critical points are worth further study.

\section{References}

1. Alwin, D. F., \& Hauser, R. M. (1975). The decomposition of effects in path analysis. American Sociological Review, 40(1), 37-47.

2. Coffman, D. L., \& MacCallum, R. C. (2005). Using parcels to convert path analysis models into latent 
variable models. Multivariate Behavioral Research, 40(2), 235-259.

3. Edwards, J. R., \& Lambert, L. S. (2007). Methods for integrating moderation and mediation: A general analytical framework using moderated path analysis. Psychological Methods, 12(1), 1-22.

4. Bryant, F. B., \& Yarnold, P. R. (1995). Principal components analysis and exploratory and confirmatory factor analysis. In L. G. Grimm \& P. R. Yarnold (Eds.), Reading and understanding multivariate analysis. Washington, DC: American Psychological Association.

5. Dunteman, G. H. (1989). Principal components analysis. Newbury Park, CA: Sage Publications.

6. Fabrigar, L. R., Wegener, D. T., MacCallum, R. C., \& Strahan, E. J. (1999). Evaluating the use of exploratory factor analysis in psychological research. Psychological Methods, 4(3), 272-299.

7. Gorsuch, R. L. (1983). Factor Analysis. Hillsdale, NJ: Lawrence Erlbaum Associates.

8. Hair, J. F., Jr., Anderson, R. E., Tatham, R. L., \& Black, W. C. (1995). Multivariate data analysis with readings (4th ed.). Upper Saddle River, NJ: PrenticeHall.

9. Hatcher, L. (1994). A step-by-step approach to using the SAS system for factor analysis and structural equation modeling. Cary, NC: SAS Institute.

10. Hutcheson, G., \& Sofroniou, N. (1999). The multivariate social scientist: Introductory statistics using generalized linear models. Thousand Oaks, CA: Sage Publications.
11. Kim, J. -O., \& Mueller, C. W. (1978a). Introduction to factor analysis: What it is and how to do it. Newbury Park, CA: Sage Publications.

12. Kim, J. -O., \& Mueller, C. W. (1978b). Factor Analysis: Statistical methods and practical issues. Newbury Park, CA: Sage Publications.

13. Lawley, D. N., \& Maxwell, A. E. (1962). Factor analysis as a statistical method. The Statistician, 12(3), 209-229.

14. Levine, M. S. (1977). Canonical analysis and factor comparison. Newbury Park, CA: Sage Publications.

15. Pett, M. A., Lackey, N. R., \& Sullivan, J. J. (2003). Making sense of factor analysis: The use of factor analysis for instrument development in health care research. Thousand Oaks, CA: Sage Publications.

16. Shapiro, S. E., Lasarev, M. R., \& McCauley, L. (2002). Factor analysis of Gulf War illness: What does it add to our understanding of possible health effects of deployment, American Journal of Epidemiology, 156, 578-585.

17. Velicer, W. F., Eaton, C. A., \& Fava, J. L. (2000). Construct explication through factor or component analysis: A review and evaluation of alternative procedures for determining the number of factors or components. In R. D. Goffin \& E. Helmes (Eds.), Problems and solutions in human assessment: Honoring Douglas Jackson at seventy. Boston, MA: Kluwer.

18. Widaman, K. F. (1993). Common factor analysis versus principal component analysis: Differential bias in representing model parameters, Multivariate Behavioral Research,

263-311. 